\title{
PERANCANGAN DAN IMPLEMENTASI MANAJEMEN DAYA LISTRIK MENGGUNAKAN ALGORITMA GREEDY UNTUK OTOMATISASI RUMAH
}

\author{
Putri Suryani Juwita ${ }^{1}$, Erwin Susanto ${ }^{2}$, Junartho Halomoan ${ }^{3}$ \\ ${ }^{1,2,3}$ Fakultas Teknik Elektro, Universitas Telkom \\ 1 putriisj_14@yahoo.co.id, ${ }^{2}$ erwinelektro@telkomuniversity.ac.id, ${ }^{3}$ junartho@telkomuniversity.ac.id
}

\begin{abstract}
Abstrak
Energi listrik merupakan kebutuhan primer bagi setiap manusia, dimana setiap aktivitas tidak terlepas dari energi listrik. Persediaan energi listrik semakin terbatas karena berasal dari sumber daya yang tidak dapat diperbarui. Maka untuk menjaga persediaan energi listrik, perlu dilakukan upaya yang dapat menunjang persediaan energi listrik secara optimal. Salah satunya dengan membuat otomatisasi rumah. Sistem otomatisasi ini diperlukan untuk memberikan kenyamanan, kemudahan, efisiensi energi dan keamanan. Otomatisasi rumah dengan pengaturan daya diharapkan menjadi solusi terbaik untuk menekan pemakaian energi. Pada penelitian ini penulis merancang dan mengimplementasikan algortima Greedy pada suatu prototipe. Pengaturan penggunaan energi listrik didasari dari permasalahan Knapsack 0/1 yang penggunaannya dibatasi sehingga menghasilkan nilai optimum. Peralatan listrik dapat dikendalikan secara otomatis menggunakan PLC (Programmable Logic Controller) berdasarkan penjadwalan yang menyesuaikan dengan biaya awal. Data yang masuk akan tersimpan dalam database sehingga pengguna dapat memantau, meninjau, serta mengontrol sistem melalui komputer atau dapat diakses melalui internet. Sebagai hasil dari penelitian ini tercipta sistem untuk manajemen daya dengan menggunakan algoritma Greedy. Sehingga membuat sistem otomatisasi rumah untuk mengendalikan peralatan listrik yang dibatasi dengan biaya tertentu. Dari hasil pengujian diperoleh waktu penjadwalan untuk menyalakan atau mematikan lampu didapatkan rata-rata 0,296 detik. Serta hasil pengujian akurasi manajemen daya algoritma Greedy mendekati $100 \%$.
\end{abstract}

Kata Kunci: otomatisasi rumah, manajemen daya listrik, knapsack problem, Algoritma Greedy.

\begin{abstract}
Electrical energy is a primary need for every human being, where every activity is inseparable from electrical energy. Supply of electrical energy are increasingly limited because they come from un-renewable resources. So to maintain the supply of electrical energy, should make efforts that can support the supply of electrical energy optimally. One of them by making home automation. This automation system is needed to provide comfort, convenience, energy efficiency and security. House automation with power management is expected to be the best solution to reduce energy consumption.

In this final project, the writer design and implement greedy algortima on a prototype. The regulation of electrical energy usage is based on Knapsack 0/1 problems whose use is limited to produce optimum value. Electrical equipment can be controlled automatically using PLC (Programmable Logic Controller) based on scheduling that adjusts to the initial cost. Incoming data will be stored in the database so that users can monitor, review, and control the system through a server on the computer or can be accessed via internet.

As results of this research is to created a system for power management by using greedy algorithm. So to created the home automation system for control the electrical equipment that is limited for certain cost. From the experimental results, it is obtained the scheduling time to turn on or turn off the lights obtained time average is 0.296 seconds. So for efficiency experimental results of power management using greedy algorithm is approaching $100 \%$.
\end{abstract}

Keywords: home automation, power management, knapsack problem, Greedy Algorithm.

1. Pendahuluan

Energi listrik merupakan kebutuhan primer bagi setiap manusia, dimana setiap aktivitas tidak terlepas dari energi listrik. Persediaan energi listrik semakin terbatas karena berasal dari sumber daya yang tidak dipat diperbarui. Untuk memperpanjang cadangan energi listrik maka pemerintah mengimbau masyarakat

Perancangan dan Implementasi Manajemen Daya Listrik Menggunakan Algoritma Greedy untuk Otomatisasi Rumah 
agar menggunakan listrik dengan bijak. Upaya lainnya, masyarakat disarankan untuk menggunakan energi alternatif. Tetapi kurangnya pengetahuan serta biaya yang mahal menghambat penggunaan energi alternatif. Oleh karena itu, otomatisasi rumah dengan pengaturan daya diharapkan menjadi solusi terbaik untuk mengurangi pemakaian energi. Otomatisasi rumah atau yang lebih sering dikenal dengan istilah rumah pintar merupakan sebuah sistem otomatisasi untuk memudahkan kontrol didalam rumah. Otomatisasi rumah diperlukan untuk memberikan kenyamanan, kemudahan, efisiensi energi dan keamanan. Untuk menciptakan otomatisasi tersebut diperlukan sebuah perangkat yang dapat bekerja secara terorganisir dimana setiap perangkat melakukan fungsi masing-masing dan dapat berkomunikasi dengan perangkat lainnya dalam sistem. Otomatisasi rumah ini mengarah bagaimana mengatur daya listrik sehingga pemakaian listrik tidak berlebih.

Pengaturan penggunaan energi listrik penelitian ini didasari dari permasalahan Knapsack, yaitu permasalahan optimasi yang objeknya dibatasi ruang atau wadah. Untuk memecahkan permasalahan tersebut, maka penelitian ini menggunakan metode greedy untuk mengoptimalkan penggunaan daya. Daya listrik dapat dibatasi sesuai dengan biaya yang diinginkan pengguna dan peralatan listrik dapat dikendalikan secara otomatis menggunakan PLC (Programmable Logic Controller). Data yang masuk akan tersimpan dalam database sehingga pengguna dapat memantau, dan mengontrol sistem melalui komputer atau melalui internet. Penelitian ini diharapkan dapat mengendalikan peralatan listrik secara otomatis berdasarkan keinginan pengguna. Dengan mengendalikan konsumsi energi listrik maka pengguna dapat meninjau pemakaian daya listrik, dapat menentukan biaya yang dikeluarkan setiap bulannya, serta dapat menghemat energi listrik.

\section{Tinjauan Pustaka}

\subsection{Home Automation}

Home Automation yang biasa dikenal dengan rumah pintar merupakan sistem otomatisasi untuk memudahkan kontrol pada rumah atau bangunan. Home automation diperlukan karena memberi kenyamanan, kemudahan, efisiensi waktu dan energi, serta keamanan yang dirasa sangat bermanfaat oleh pengguna.

Dalam pengaplikasian, Home automation bekerja dengan mengintegrasikan perangkat listrik satu dengan yang lain dalam sebuah rumah. Perangkat tersebut dihubungkan melalui jaringan komputer atau dapat juga dikontrol melalui jaringan internet sehingga dapat diakses pengguna dimanapun dan kapanpun. Home automation memberikan fasilitas yang diinginkan secara otomatis dan sudah terprogram.

\subsection{Knapsack Problem}

Knapsack Problem adalah suatu permasalahan optimasi pada pemilihan objek yang dapat disimpan dimasukkan ke dalam sebuah wadah yang memiliki keterbatasan ruang atau daya tampung. Sejumlah objek memiliki berat dan sebuah nilai yang digunakan untun menentukan prioritasnya dalam pemilihan. Wadah ini memiliki nilai kostanta yang membatasi jumlah barang yang dapat dimasukkan, sehingga menghasilkan hasil yang optimum tetapi tidak melebihi kapasitas wadah.

Pada penelitian ini diterapkan prinsip 0/1 knapsack. 0/1 knapsack problem adalah salah satu permasalahan dalam knapsack problem, yaitu membatasi jumlah pengambilan barang yang akan dimasukkan ke dalam wadah untuk setiap jenisnya dengan nol atau satu kali. Permasalahan 0/1 knapsack dipandang sebagai mencari himpunan bagian dari keseluruhan objek yang muat ke dalam knapsack dan memberikan total keuntungan terbesar. Total bobot objek yang dimasukkan ke dalam knapsack tidak boleh melebihi kapasitas knapsack.

\subsection{Algoritma Greedy}

Metode greedy merupakan teknik untuk memecahkan beragam permasalahan untuk mencapai solusi yang optimal (maksimum atau minimum). Metode greedy menyelesaikan permasalahan langkah demi langkah, pada setiap langkah terdapat banyak pilihan yang perlu dieksplorasi. Oleh karena itu, pada setiap langkah harus dibuat keputusan yang terbaik dalam menentukan pilihan. Metode greedy merupakan metode yang sering digunakan untuk menyelesaikan masalah knapsack 0/1. Metode ini tidak selalu memberikan solusi optimal, tetapi dapat menghasilkan solusi optimal lokal yang mendekati solusi optimal global dengan waktu yang layak.

Untuk memilih objek yang akan dimasukkan ke dalam knapsack terdapat beberapa strategi metode greedy yaitu: Greedy by profit, Greedy by weight, Greedy by density. Pada penelitian ini hanya menerapkan metode greedy by density. Greedy by density merupakan salah satu permasalahan knapsack yang diisi dengan objek yang mempunyai densitas terbesar pada setiap tahap. Memilih objek yang mempunyai keuntungan tiap unit berat terbesar untuk memaksimumkan keuntungan. Tahap pertama yang dilakukan adalah mencari nilai profit tiap unit dari tiap-tiap objek. Kemudian objek-objek tersebut diurutkan berdasarkan densitasnya. Kemudian diambil satu demi satu objek yang dapat ditampung oleh knapsack sampai knapsack penuh atau sudah tidak ada

\section{Jurnal Penelitian dan Pengembangan Telekomunikasi, Kendali, Komputer, Elektrik, dan Elektronika (TEKTRIKA)} Juli 2017 - Volume 2, Nomor 2 
objek lagi yang bisa dimasukkan. Strategi tersebut yang digunakan dalam penelitian.

\subsection{PLC}

PLC (Programmable Logic Controller) adalah suatu mikroprosesor yang digunakan untuk otomasi proses industri. PLC banyak digunakan pada aplikasiaplikasi industri. Dengan kata lain, hampir semua aplikasi yang memerlukan kontrol listrik atau elektronik membutuhkan PLC.

PLC dirancang multi input dan multi output (MIMO), tingkat suhu yang tinggi, kebal terhadap noise, dan tahan terhadap getaran dan benturan. Bahasa pemrograman yang digunakan adalah ladder diagram (diagram tangga), yang hanya berisi inputproses-output. PLC Omron tipe $\mathrm{CP} 1 \mathrm{H}$ memiliki 40 Input/Output (I/O), 24 input dan 16 output. Komunikasi $\mathrm{CP} 1 \mathrm{H}$ yang digunakan adalah ethernet dua port.

\subsection{Visual Studio}

Microsoft Visual Studio merupakan sebuah perangkat lunak yang dapat digunakan untuk melakukan pengembangan aplikasi, dalam bentuk aplikasi console, aplikasi Windows, ataupun [[[ web. Compiler yang dimasukkan ke dalam paket salah satunya adalah Visual Basic.NET. Visual Studio juga memiliki Visual Database Tools untuk membuat table, queri, diagram database, dan fitur-fitur tambahan untuk membuat database. Visual Basic.Net merupakan salah satu bahasa pemrograman yang berorientasi pada objek atau OOP (Object Oriented Proramming) dan untuk database menggunakan bahasa SQL (Structure Query Language) merupakan sebuah bahasa yang digunakan untuk mengakses data dalam basis data relasional yang digunakan untuk mengakses database.

\section{Metodologi Penelitian}

\subsection{Perancangan Sistem}

Sistem otomatisasi rumah untuk pengaturan daya akan diaplikasikan pada prototipe rumah yang dibuat menggunakan triplek dengan panjang $120 \mathrm{~cm}$, lebar $200 \mathrm{~cm}$ dan tebal $1,2 \mathrm{~cm}$. Prototipe rumah memiliki luas 100x150cm dan memiliki 10 lampu, dan empat stopkontak yang akan dikontrol untuk bahan penelitian. Pengaturan daya listrik yang dirancang padarumah dengan tegangan $220 \mathrm{~V}$. Pengaturan daya dirancang sesuai dengan biaya masukan, nama peralatan listrik yang disertai dengan daya dan waktu pemakaian. Semua persyaratan tersebut perlu dijadwalkan terlebih dahulu, lalu akan tersimpan dalam database yang dapat diakses melalui internet.

Berikut adalah alamat input analog yang disertai dengan nama stopkontak yang akan dikontrol oleh PLC. Input analog PLC akan masuk ke data memory (DM) untuk menyimpan data yang nantinya sebagai masukan algoritma.

Tabel 1. Penamaan Perangkat

\begin{tabular}{|c|c|c|}
\hline No. & Nama Perangkat & Alamat PLC \\
\hline 1 & Lampu Teras & ClO 100.00 \\
\hline 2 & Lampu Garasi & $\mathrm{ClO} 100.01$ \\
\hline 3 & Lampu Ruang Tamu & $\mathrm{ClO} 100.02$ \\
\hline 4 & Lampu Ruang Keluarga & $\mathrm{ClO} 100.03$ \\
\hline 5 & Lampu Kamar Tidur 1 & $\mathrm{ClO} 100.04$ \\
\hline 6 & Lampu Kamar Tidur 2 & $\mathrm{ClO} 100.05$ \\
\hline 7 & Lampu Kamar Tidur 3 & $\mathrm{ClO} 100.06$ \\
\hline 8 & Lampu Kamar Mandi & $\mathrm{ClO} 100.07$ \\
\hline 9 & Lampu Ruang Makan & $\mathrm{ClO} 101.00$ \\
\hline 10 & Lampu Dapur & $\mathrm{ClO} 101.01$ \\
\hline 11 & Stopkontak Kamar Tidur 2 & $\mathrm{ClO} 101.05$ \\
\hline 12 & Stopkontak Kamar Tidur 3 & $\mathrm{ClO} 101.03$ \\
\hline 13 & Stopkontak Ruang Keluarga 1 & $\mathrm{ClO} 101.06$ \\
\hline 14 & Stopkontak Ruang Keluarga 2 & $\mathrm{ClO} 101.04$ \\
\hline
\end{tabular}

Tabel 2. Input Analog

\begin{tabular}{|c|c|c|c|}
\hline No. & I/O Poin & Nama Perangkat & $\begin{array}{c}\text { Alamat Analog } \\
\text { Input PLC }\end{array}$ \\
\hline 1 & Analog Input 0 & Stopkontak kamar tidur 3 & ClO 200 \\
\hline 2 & Analog Input 1 & Stopkontak kamar tidur 2 & $\mathrm{ClO} \mathrm{201}$ \\
\hline 3 & Analog Input 2 & Stopkontak keluarga 2 & $\mathrm{ClO} \mathrm{202}$ \\
\hline 4 & Analog Input 3 & Stopkontak keluarga 1 & $\mathrm{ClO} \mathrm{203}$ \\
\hline
\end{tabular}
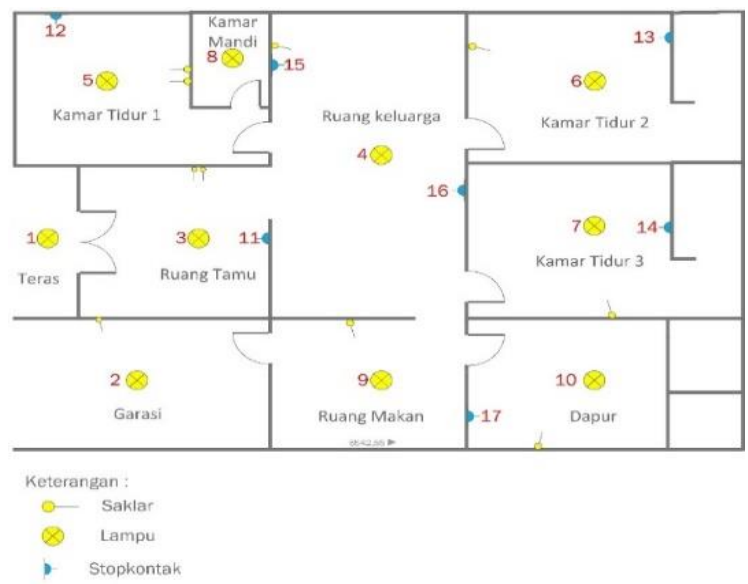

Gambar 1. Prototipe Denah Rumah

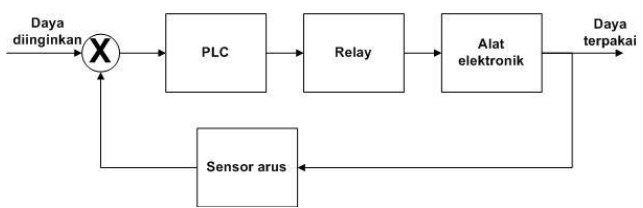

Gambar 2. Diagram Blok Sistem

\subsection{Diagram Blok}

Diagram blok keseluruhan sistem ini yaitu: PLC sebagai kontroler, digunakan untuk mengaktifkan serta 
me-non-aktifkan peralatan listrik. Apabila sistem kelebihan beban maka PLC memerintahkan relai sebagai aktuator untuk memutuskan arus, relai dipasang pada empat buah stopkontak dan 10 buah lampu. Umpan balik sistem ini yaitu sensor arus, digunakan untuk mengetahui arus yang terpakai pada empat buah stopkontak yang terpasang pada peralatan listrik, nilai tersebut akan diubah kembali menjadi daya listrik. Daya yang diinginkan akan dibandingkan dengan daya yang terpakai, apabila jumlah daya yang terpakai kurang dari daya awal maka sistem akan terus mengulang hingga jumlah daya yang terpakai menedekati daya awal.

\subsection{Diagram Alir Sistem}

Ilustrasi kerja sistem yaitu, sistem dimulai saat pengguna memberi masukan jumlah biaya awal dan menjadwalkan peralatan listrik pada Windows Application, lalu jumlah tersebut dikonversikan menjadi daya. Empat buah stopkontak akan dipasang sensor arus, nilai tersebut digunakan sebagai masukan untuk mengolah algoritma greedy, algoritma ini bertujuan untuk mengoptimalkan penggunaan daya listrik. Pada perhitungan algoritma greedy hasil yang didapat tidak selalu sama persis dengan nilai masukan (daya awal), tetapi pada perhitungannya dicari hasil yang paling mendekati nilai yang dikehendaki dengan selisih sekecil mungkin. Nilai dari sensor arus akan diubah menjadi daya, nilai daya tersebut akan dibandingkan dengan daya awal. Apabila daya yang terpakai melebihi dari daya awal maka secara otomatis relai memutus arus pada peralatan listrik tersebut. Hasil dari sistem ini, berupa penjadwalan ulang yang disertai dengan pengurangan waktu pemakaian pada peralatan listrik tertentu. Pengguna dapat mengontrol sistem ini melalui Windows Application atau melalui internet. Ilustrasi sistem secara umum dapat dilihat pada Gambar 3.

\subsection{Perancangan Perangkat Keras}

Komponen dari desain sistem yang dirancang adalah sebagai berikut:

- PLC merupakan sistem elektronik yang berfungsi untuk mengontrol sistem. Pada penelitian ini menggunakan PLC Omron CP1H.

- Sensor arus yang digunakan adalah ACS712 5A digunakan untuk mendeteksi pemakaian arus.

- $\quad$ PC digunakan sebagai server dan dapat juga untuk memonitor sistem dan digunakan sebagai tampilan Windows Application utuk penjadwalan peralatan listrik yang akan digunakan.

- Relai yang digunakan yaitu relai Omron 24volt yang berfungsi sebagai menghubungkan dan memutuskan arus listrik. Relai bekerja ketika PLC. Relai akan dihubungkan dengan stopkontak.

- Peralatan listrik digunakan sebagai beban dari sistem. Peralatan listrik yang dipakai yaitu alat yang biasa digunakan untuk rumah tangga.

- Komunikasi antara Visual Studio dengan PLC menggunakan OPC server dan OPC klien.

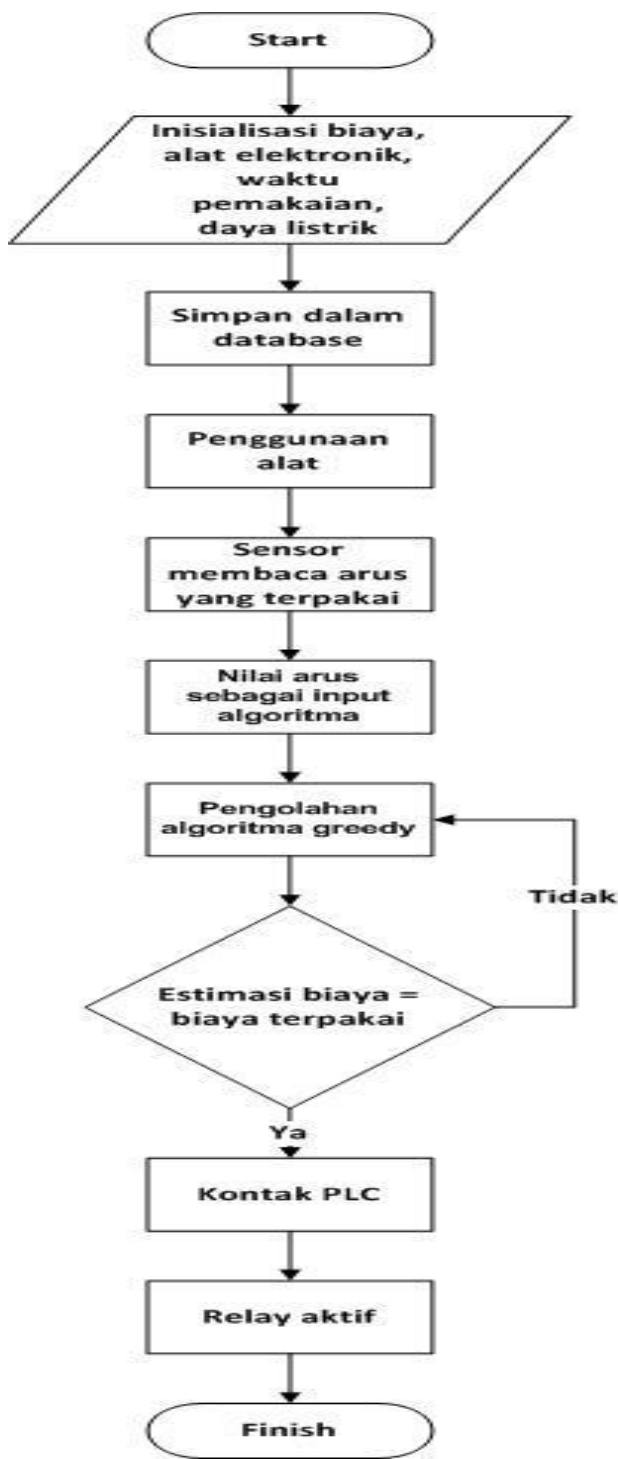

Gambar 3. Diagram Alir Sistem

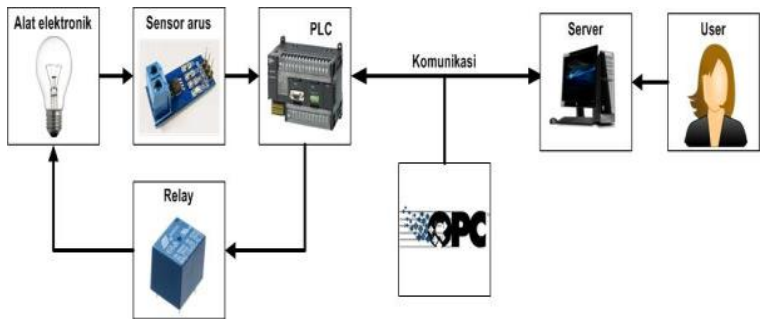

Gambar 4. Desain Perangkat Keras

\section{Jurnal Penelitian dan Pengembangan Telekomunikasi, Kendali, Komputer, Elektrik, dan Elektronika} (TEKTRIKA)

Juli 2017 - Volume 2, Nomor 2 


\subsection{Perancangan Perangkat Lunak}

Flowchart perancangan algoritma greedy diilustrasikan sebagai berikut, daya pemakaian akan dipisah menjadi dua bagian daya yang terjadwal dengan daya yang terhubung ke stopkontak, nilai daya yang digunakan untuk stopkontak yaitu hasil pengurangan daya awal dengan daya yang sudah terjadwal. Sistem akan membagi daya stopkontak menjadi 4 zona waktu: waktu pagi diantara jam 00:0106:00 dengan perbandingan daya pemakaian 1/8, waktu siang diantara jam 06:01-12:00 dengan perbandingan daya pemakaian $2 / 8$, waktu sore diantara jam 12:01-18:00 dengan perbandingan daya pemakaian $2 / 8$, dan waktu malam diantara jam 18:0124:00 dengan perbandingan daya pemakaian 3/8. Kemudian algoritma akan membandingkan daya pada setiap stopkontak, apabila daya pada stop kontak tertentu tidak melebihi daya yang ditentukan maka kondisinya adalah true, sedangkan apabila daya pada stopkontak tertentu melebihi daya daya yang sudah ditentukan maka kondisinya adalah false nilai ini akan mengaktifkan relai untuk memutuskan arus listrik stopkontak. Hasil yang didapat adalah status pada setiap stopkontak nilainya berupa true atau false.

Kelemahan dari sistem ini yaitu, ketika peralatan listrik memiliki daya tertentu dimana daya tersebut sudah melebihi daya yang telah ditentukan, maka peralatan listrik tersebut akan mati walaupun sedang digunakan, tetapi stopkontak yang lain tetap akan menyala dimana peralatan listrik tersebut memiliki stopkontak yang lain tetap akan menyala dimana peralatan listrik tersebut memiliki daya yang ditentukan.

\section{Implementasi dan Pengujian}

\subsection{Pengujian Penjadwalan Lampu}

Pada pengujian ini ingin membuktikan output yang dijadwalkan pada Visual Studio yang terkoneksi dengan PLC. Pengujian dilakukan dengan menghubungkan peralatan listrik yang terdiri dari 10 buah lampu dengan daya $15 \mathrm{~W}$ att. Proses pertama data yang dijadwalkan akan disimpan pada database, lalu dikirim ke PLC untuk mengaktifkan relai.

\section{Hasil pengujian}

\section{Penggunaan Rp. 100.000,00}

Hari $=$ Jumat

Tarif dasar listrik $=$ Rp. 1467,28/KWh

Batas beban per bulan $=64,3 \mathrm{KWh}$

Batas beban per hari $=2,143 \mathrm{KWh}$

2. Penggunaan Rp. 200.000,00

Hari $=$ Sabtu

Tarif dasar listrik $=$ Rp. 1467,28 / KWh
Batas beban per bulan $=96,4 \mathrm{KWh}$

Batas beban per hari $=3,21 \mathrm{KWh}$

\section{Analisis}

Berdasarkan hasil pengujian, sistem berjalan sesuai dengan jadwal yang diatur oleh PLC. Dilihat dari pengujian pada hari pertama, waktu yang diterima relai

untuk menyalakan lampu hari pertama didapatkan delay rata-rata 0,295 detik, sedangkan untuk waktu dengan mematikan lampu didapatkan delay rata-rata 0,297 detik. Untuk hari kedua waktu yang diterima relai untuk menyalakan lampu didapatkan delay ratarata 0,278 detik, sedangkan untuk waktu dengan mematikan lampu didapatkan delay rata-rata 0,298 detik.

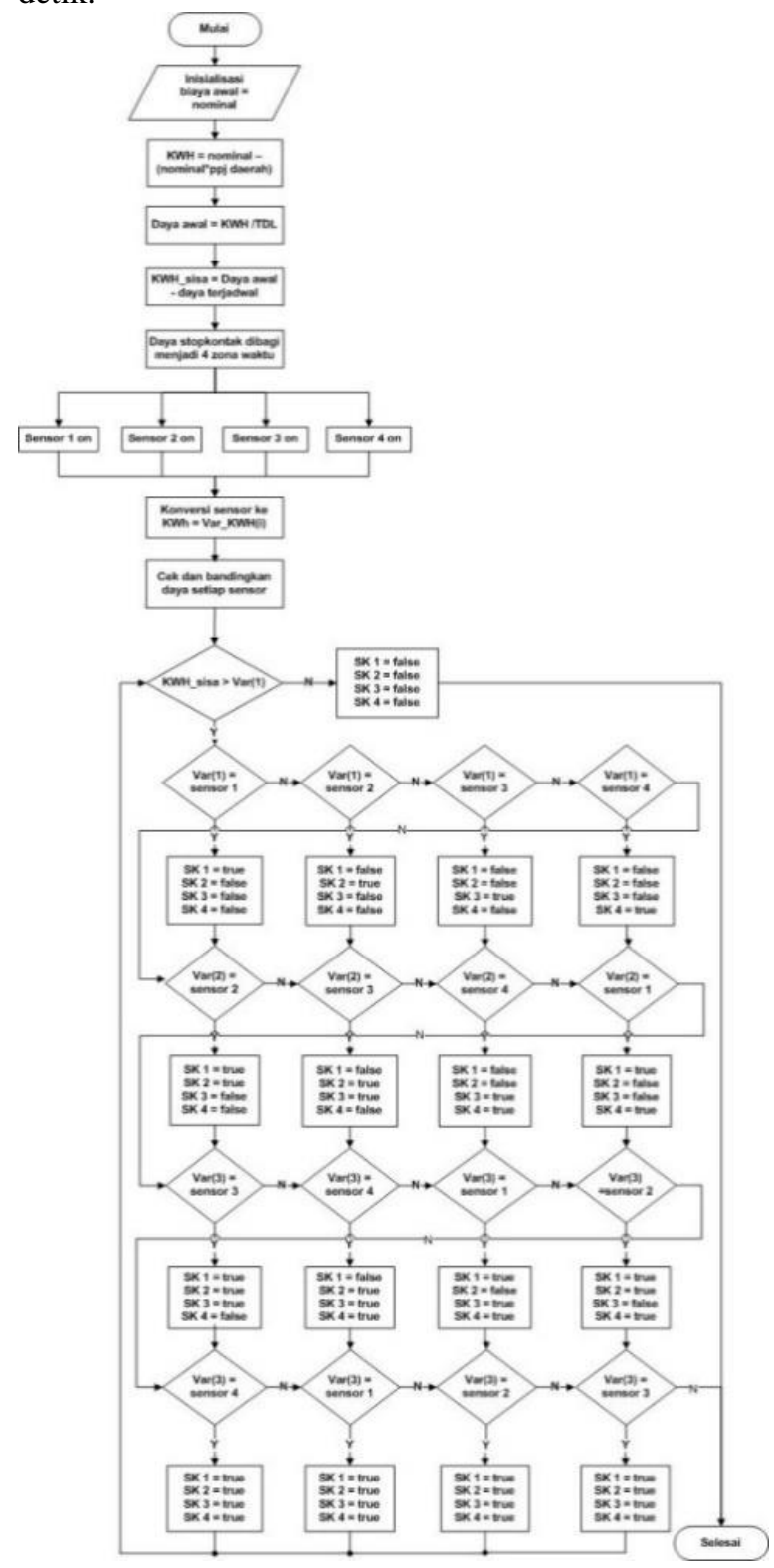

Gambar 5. Flowchart algoritma greedy 


\subsection{Pengujian Algoritma Greedy}

Pengujian manajemen daya dengan menggunakan algoritma greedy dibagi menjadi tiga zona waktu, yaitu: siang, sore, dan malam. Dengan biaya awal Rp. 200.000/bulan, dimana tarif dasar listrik tahun ini sebesar Rp. 1467,28 / KWh. Sehingga didapatkan batas beban per bulan sebesar 96,4 KWh, dan batas beban per hari sebesar 3,21 KWh. Batas beban untuk stopkontak yaitu, hasil pengurangan dari batas beban per hari dengan daya yang terjadwal, sehingga didapatkan 2,22 KWh.

Tabel 3. Pengujian dengan algoritma greedy ke-1

\begin{tabular}{|c|l|c|c|c|}
\hline $\begin{array}{c}\text { Stop } \\
\text { kontak }\end{array}$ & Nama Beban & $\begin{array}{c}\text { Daya } \\
\text { terbaca }\end{array}$ & Durasi & Total daya \\
\hline 1 & Dispenser & 286,59 Watt & 45 menit & $0,215 \mathrm{KWh}$ \\
\hline 2 & Setrika & 320,56 Watt & 45 menit & $0,240 \mathrm{KWh}$ \\
\hline 3 & Kipas angin & 15,12 Watt & 120 menit & $0,03 \mathrm{KWh}$ \\
\hline 4 & Penanak nasi & 93,25 Watt & 45 menit & $0,07 \mathrm{KWh}$ \\
\hline \multicolumn{4}{|c|}{ Jumlah daya terpakai } & $0,555 \mathrm{KWh}$ \\
\hline
\end{tabular}

Tabel 4. Pengujian tanpa algoritma greedy ke-1

\begin{tabular}{|c|l|c|c|c|}
\hline $\begin{array}{c}\text { Stop } \\
\text { kontak }\end{array}$ & Nama Beban & $\begin{array}{c}\text { Daya } \\
\text { terbaca }\end{array}$ & Durasi & Total daya \\
\hline 1 & Dispenser & 286,59 Watt & 60 menit & $0,286 \mathrm{KWh}$ \\
\hline 2 & Setrika & 320,56 Watt & 60 menit & $0,35 \mathrm{KWh}$ \\
\hline 3 & Kipas angin & 15,12 Watt & 180 menit & $0,045 \mathrm{KWh}$ \\
\hline 4 & Penanak nasi & 93,25 Watt & 60 menit & $0,093 \mathrm{KWh}$ \\
\hline \multicolumn{4}{|c|}{ Jumlah daya terpakai } & $0,774 \mathrm{KWh}$ \\
\hline
\end{tabular}

Tabel 5. Pengujian dengan algoritma greedy ke-2

\begin{tabular}{|c|l|c|c|c|}
\hline $\begin{array}{c}\text { Stop } \\
\text { kontak }\end{array}$ & $\begin{array}{c}\text { Nama } \\
\text { Beban }\end{array}$ & Daya terbaca & Durasi & Total daya \\
\hline 1 & Dispenser & 289,46 Watt & 75 menit & $0,362 \mathrm{KWh}$ \\
\hline 2 & Monitor & 6,32 Watt & 135 menit & $0,014 \mathrm{KWh}$ \\
\hline 3 & Kipas angin & 16,17 Watt & 105 menit & $0,028 \mathrm{KWh}$ \\
\hline 4 & Pemanas air & 598 Watt & 15 menit & $0,15 \mathrm{KWh}$ \\
\hline \multicolumn{4}{|c|}{ Jumlah daya terpakai } & $0,554 \mathrm{KWh}$ \\
\hline
\end{tabular}

Tabel 6. Pengujian tanpa algoritma greedy ke-2

\begin{tabular}{|c|l|c|c|c|}
\hline $\begin{array}{c}\text { Stop } \\
\text { kontak }\end{array}$ & Nama Beban & $\begin{array}{c}\text { Daya } \\
\text { terbaca }\end{array}$ & Durasi & Total daya \\
\hline 1 & Dispenser & 289,46 Watt & 90 menit & $0,434 \mathrm{KWh}$ \\
\hline 2 & Monitor & 6,32 Watt & 120 menit & $0,013 \mathrm{KWh}$ \\
\hline 3 & Kipas angina & 16,17 Watt & 120 menit & $0,032 \mathrm{KWh}$ \\
\hline 4 & Pemanas air & 598 Watt & 15 menit & $0,15 \mathrm{KWh}$ \\
\hline \multicolumn{4}{|c|}{ Jumlah daya terpakai } & $0,629 \mathrm{KWh}$ \\
\hline
\end{tabular}

Tabel 7. Pengujian dengan algoritma greedy ke-3

\begin{tabular}{|c|l|c|c|c|}
\hline $\begin{array}{c}\text { Stop } \\
\text { kontak }\end{array}$ & $\begin{array}{c}\text { Nama } \\
\text { Beban }\end{array}$ & Daya terbaca & Durasi & Total daya \\
\hline 1 & Dispenser & 289,46 Watt & 120 menit & $0,579 \mathrm{KWh}$ \\
\hline 2 & Monitor & 6,32 Watt & 240 menit & $0,025 \mathrm{KWh}$ \\
\hline 3 & Kipas angin & 16,17 Watt & 210 menit & $0,057 \mathrm{KWh}$ \\
\hline 4 & $\begin{array}{l}\text { Penanak } \\
\text { nasi }\end{array}$ & 94 Watt & 120 menit & $0,188 \mathrm{KWh}$ \\
\hline \multicolumn{4}{|c|}{ Jumlah daya terpakai } & $0,824 \mathrm{KWh}$ \\
\hline
\end{tabular}

Tabel 6. Pengujian tanpa algoritma greedy ke-3

\begin{tabular}{|c|l|c|c|c|}
\hline $\begin{array}{c}\text { Stop } \\
\text { kontak }\end{array}$ & $\begin{array}{c}\text { Nama } \\
\text { Beban }\end{array}$ & Daya terbaca & Durasi & Total daya \\
\hline 1 & Dispenser & 289,46 Watt & 120 menit & $0,579 \mathrm{KWh}$ \\
\hline 2 & Monitor & 6,32 Watt & 240 menit & $0,025 \mathrm{KWh}$ \\
\hline 3 & Kipas angin & 16,17 Watt & 240 menit & $0,065 \mathrm{KWh}$ \\
\hline 4 & $\begin{array}{l}\text { Penanak } \\
\text { nasi }\end{array}$ & 94 Watt & 120 menit & $0,188 \mathrm{KWh}$ \\
\hline \multicolumn{4}{|c|}{ Jumlah daya terpakai } & $0,857 \mathrm{KWh}$ \\
\hline
\end{tabular}

Tabel 8. Pengujian penjadwalan listrik pertama

\begin{tabular}{|c|c|c|c|c|c|c|c|}
\hline No & Nama Peralatan & Daya & $\begin{array}{l}\text { Jam } \\
\text { mulai }\end{array}$ & $\begin{array}{c}\text { Jam } \\
\text { berakhi }\end{array}$ & $\begin{array}{c}\text { Jumlah } \\
\text { daya }\end{array}$ & $\begin{array}{l}\text { Delay } \\
\text { nyala }\end{array}$ & $\begin{array}{c}\text { Delay } \\
\text { mati }\end{array}$ \\
\hline 1 & Lampu teras & 15 Watt & 17:00 & $23: 00$ & $0.09 \mathrm{KWh}$ & 0,3 detik & 0,3 detik \\
\hline 2 & & & 17:00 & $23: 00$ & $0,09 \mathrm{KWh}$ & 0,29 detik & 0,3 detik \\
\hline 3 & Lampu ruang tamu & 155 Watt & 5:00 & 7:00 & $0,03 \mathrm{KWh}$ & 0,3 detik & $0,3 \mathrm{~d}$ \\
\hline 4 & Lampu ruang & 115 W/att & 17:00 & $23: 00$ & $0,09 \mathrm{KWh}$ & 0,3 detik & 0,29 detik \\
\hline 5 & keluarga & & 5:00 & 7:00 & $0,03 \mathrm{KWh}$ & 0,3 detik & 0,29 detik \\
\hline 6 & Lampu K & & 17:00 & $23: 00$ & $0,09 \mathrm{KWh}$ & 0,3 detik & 0,3 detik \\
\hline 7 & & 15 Watt & 5:00 & $7: 00$ & $0,03 \mathrm{KWh}$ & 0,29 detik & 0,3 detik \\
\hline 8 & $\operatorname{Lamp}$ & $15 \mathrm{~W}=\mathrm{z}-\mathrm{s}=$ & 17:00 & $23: 00$ & $0,09 \mathrm{KWh}$ & 0,3 detik & 0,29 detik \\
\hline 9 & & & 5:00 & 7:00 & $0,03 \mathrm{KWh}$ & 0,3 detik & 0,29 detik \\
\hline 10 & Lam & & 17:00 & $23: 00$ & $0,09 \mathrm{KWh}$ & 0,29 detik & 0,29 detik \\
\hline 11 & & & 5:00 & 7:00 & & 0,3 & 0,29 detik \\
\hline 12 & Lampu & 15 Watt & 17:00 & $23: 00$ & $0.09 \mathrm{KWh}$ & 0,3 & 0,29 detik \\
\hline 13 & Lam & & 17:00 & $23: 00$ & $0.09 \mathrm{KWh}$ & 0,3 detik & 0,3 detik \\
\hline 14 & & W & 5:00 & $7: 00$ & $0,03 \mathrm{KWh}$ & 0,29 detik & 0,3 detik \\
\hline 15 & & & 17:00 & $23: 00$ & $0.09 \mathrm{KWh}$ & 0,28 detik & 0,3 detik \\
\hline 16 & & & 5:00 & 7:00 & $0,03 \mathrm{KWh}$ & 0,28 detik & 0,3 detik \\
\hline \multicolumn{5}{|c|}{ otal/rata-rata } & $1.02 \mathrm{KWh}$ & $\begin{array}{l}0,295 \\
\text { detik }\end{array}$ & $\begin{array}{l}0,297 \\
\text { detik }\end{array}$ \\
\hline
\end{tabular}

Tabel 9. Pengujian penjadwalan listrik kedua

\begin{tabular}{|c|c|c|c|c|c|c|c|}
\hline No & $\begin{array}{c}\text { Nama } \\
\text { Peralatan }\end{array}$ & Daya & $\begin{array}{l}\text { Jam } \\
\text { mulai }\end{array}$ & $\begin{array}{c}\text { Jam } \\
\text { berakhir }\end{array}$ & Jumlah daya & $\begin{array}{l}\text { Delay } \\
\text { nyala }\end{array}$ & $\begin{array}{l}\text { Delay } \\
\text { mati }\end{array}$ \\
\hline 1 & Lampu teras & 15 Watt & $17: 00$ & \begin{tabular}{|l|}
$23: 00$ \\
\end{tabular} & $0.09 \mathrm{KWh}$ & 0,3 detik & 0,3 detik \\
\hline 2 & Lampu ruang & & $17: 00$ & $23: 00$ & $0,09 \mathrm{KWh}$ & 0,29 detik & 0,29 detik \\
\hline 3 & $\operatorname{tamu}$ & & 5:00 & 7:00 & 0,03 KWh & 0,3 detik & 0,29 detik \\
\hline 4 & $\begin{array}{l}\text { Lampu ruang } \\
\text { keluarga }\end{array}$ & |15 Watt & $17: 00$ & 23:00 & $0,09 \mathrm{KWh}$ & 0,31 detik & 3 detik \\
\hline 5 & Lampu & $15 \mathrm{Wr}$ & $17: 00$ & $23: 00$ & $0,03 \mathrm{KWh}$ & 0,29 detik & 0,3 detik \\
\hline 6 & Kamar tidur 1 & & $5: 00$ & $7: 00$ & $0,09 \mathrm{KWh}$ & 0,29 detik & 0,3 detik \\
\hline 7 & Lampu & & $17: 00$ & $23: 00$ & $0,03 \mathrm{KWh}$ & 0,3 detik & 0,3 detik \\
\hline 8 & Kamar tidur 2 & & 5:00 & 7:00 & $0,09 \mathrm{KWh}$ & 0,3 detik & 0,3 detik \\
\hline 9 & Lampu & & $17: 00$ & $23: 00$ & $\begin{array}{l}0,03 \mathrm{KWh} \\
\end{array}$ & 0,29 detik & 0,3 detik \\
\hline 10 & Kamar tidur 3 & & $5: 00$ & $7: 00$ & $0,09 \mathrm{KWh}$ & 0,29 detik & 0,29 detik \\
\hline 11 & Lampu garasi & 15 Watt & $17: 00$ & $23: 00$ & $0.09 \mathrm{KWh}$ & 0,3 detik & 0,3 detik \\
\hline 12 & Lampu ruang & & 16:00 & 22:00 & $0,03 \mathrm{KWh}$ & 0,3 detik & 0,3 detik \\
\hline 13 & makan & & $5: 00$ & $7: 00$ & $0.09 \mathrm{KWh}$ & 0,29 detik & 0,3 detik \\
\hline 14 & & & $16: 00$ & $22: 00$ & $0,09 \mathrm{KWh}$ & 0,29 detik & 0,3 detik \\
\hline 15 & pur & 115 & $17: 00$ & $23: 00$ & 0,03 KWh & 0,29 detik & 0,3 detik \\
\hline \multicolumn{5}{|c|}{ Total/rata-rata } & $\begin{array}{l}0,99 \\
\text { KWh }\end{array}$ & $\begin{array}{l}0,278 \\
\text { detik }\end{array}$ & $\begin{array}{l}0,298 \\
\text { detik }\end{array}$ \\
\hline
\end{tabular}

Pengujian Siang

Jam = 06:01-12:00

Analisis

Batas beban stopkontak $=0,555 \mathrm{KWh}$

Berdasarkan hasil pengujian sistem, didapatkan nilai yang terbaca setiap stopkontak yang telah diatur oleh PLC. Pengujian waktu pagi, total penggunaan daya dengan algoritma greedy sebesar $0,555 \mathrm{KWh}$, sedangkan total penggunaan daya tanpa algoritma greedy sebesar $0,774 \mathrm{KWh}$, dengan batas stopkontak waktu pagi sebesar 0,555 KWh. Akurasi manajemen daya algoritma greedy $100 \%$.

Pengujian Sore

$\mathrm{Jam}=12: 01-18: 00$

Batas beban stopkontak $=0,555 \mathrm{KWh}$

Analisis

Berdasarkan hasil pengujian sistem, didapatkan nilai yang terbaca setiap stopkontak yang telah diatur oleh PLC. Pengujian waktu siang, total penggunaan daya dengan algoritma greedy sebesar $0,554 \mathrm{KWh}$, sedangkan total penggunaan daya tanpa algoritma greedy sebesar 0,629 KWh, dengan batas stop kontak 
waktu siang sebesar 0,555 KWh. Akurasi manajemen daya algoritma greedy sebesar 99,8\%.

\section{Pengujian Malam}

Jam $=18: 01-24: 00$

\section{Analisis}

Batas beban stopkontak $=0,825 \mathrm{KWh}$

Berdasarkan hasil pengujian sistem, didapatkan nilai yang terbaca setiap stopkontak yang diatur oleh PLC. Pengujian waktu malam, total penggunaan daya dengan algoritma greedy sebesar $0,824 \mathrm{KWh}$, sedangkan total penggunaan daya tanpa algoritma greedy sebesar 0,857 $\mathrm{KWh}$, dengan batas stopkontak waktu malam sebesar $0,825 \mathrm{KWh}$.

\section{Kesimpulan}

Diperoleh kesimpulan di antaranya:

1. Waktu untuk menyalakan lampu melalui PLC membutuhkan waktu yang lebih lama. Delay PLC saat menyalakan atau mematikan lampu didapatkan rata-rata 0,296 detik.

2. Algoritma greedy dapat mengatur penggunaan beban peralatan listrik agar sesuai dengan batas.

\section{Daftar Pustaka}

[1] Sansani, Sesdika (2008): Penggunaan Aritmetika Modulo dan Balikan Modulo pada Modifikasi Algoritma Knapsack. Bandung: Teknik Informatika Institut Teknologi Bandung.

[2] Firdaus (2006): 7 Jam Belajar Interaktif Visual Basic 6.0 untuk Orang Awam. Palembang: Maxico.

[3] Nugroho, Adi (2010): Mengembangkan Aplikasi Basis Data Menggunakan C\# dan SQL Server.

[4] Omron (2005): CP1H CPU Unit Operation Manual.

[5] Sianipar, R.H (2014): Pemrograman Visual Basic.NET. Bandung: Informatika Bandung.

[6] Lee, Christopher (2016): Belajar Visual Basic 2015 Step-by-Step. Jakarta: PT. Gramedia.

[7] Taqy, Mochamad Abiyan (2012): Perancangan dan Implementasi Algoritma Greedy Pada Manajemen Daya Listrik Gedung Perkantoran/Rumah. Telkom University Bandung 